CORIGINAL ARTICLE

Volume 15 Issue 12020

DOI: 10.21315/aos2020.15.1.402

ARTICLE INFO

Submitted: 06/11/2019

Accepted: $31 / 05 / 2020$

Online: $15 / 07 / 2020$

\section{Oral Cancer Awareness and Knowledge among Marginalised Group in Sungai Petani, Kedah, Malaysia}

\author{
Sa'adiah Shahabudin ${ }^{a}$, Noorsuzana Mohd Shariff ${ }^{b}$, Husniyati Roslana, \\ Hazwani Ahmad Yusof ${ }^{b}$, Rohayu Hami ${ }^{b}$
}
${ }^{a}$ Craniofacial and Biomaterial Science Cluster, Advanced Medical and Dental Institute, Universiti Sains Malaysia, 13200 Kepala Batas, Pulau Pinang, Malaysia
${ }^{b}$ Healthy Lifestyle Science Cluster, Sains@Bertam, Advanced Medical and Dental Institute, Universiti Sains Malaysia, 13200 Kepala Batas, Pulau Pinang, Malaysia

${ }^{*}$ Corresponding author: saadiahsh@usm.my

To cite this article: Shahabudin S, Mohd Shariff N, Roslan H, Ahmad Yusof H, Hami R (2020). Oral cancer awareness and knowledge among marginalised group in Sungai Petani, Kedah, Malaysia. Arch Orofac Sci, 15(1): 11-21. https://doi.org/10.21315/aos2020.15.1.402

To link to this article: https://doi.org/10.21315/aos2020.15.1.402

\begin{abstract}
Oral cancer is the sixth common type of cancer in the world. In Malaysia, it contributes to about $10.6 \%$ death in government hospitals. Mortality and morbidity due to oral cancer could be reduced if it could be detected at an early stage. Socioeconomic status is an important determinant of incidence of head and neck cancer. This study investigated the awareness and knowledge of low-income community in Sungai Petani, Kedah, Malaysia and its associated factors. This cross-sectional study used questionnaire with convenient sampling among the community of Paya Nahu who attended our health campaign. Their awareness was fairly good (7, however, their in-depth knowledge on oral cancer was poor with a mean score of 9.68 (SD 4.46). Smoking was the well-known risk factor $(64.4 \%)$, about half of them knew the sign and symptoms of oral cancer, $77.1 \%$ agreed with benefit of early detection and $55 \%$ of them knew that mouth self-examination is a step to prevent oral cancer. The unemployed has 0.33 time the odds compared to the employed to have good knowledge (95\% CI: $0.120,0.890, p$-value $<0.029$ ) when adjusted for occupation. Media and health campaign were the main sources of information. It is essential to increase awareness and knowledge on oral cancer among the low socioeconomic status community. Since low socioeconomic standard is a factor which restricts health seeking behaviour, outreach programmes such as informative media and improved health campaign should be planned accordingly.
\end{abstract}

Keywords: Awareness; knowledge; marginalised group; oral cancer; socioeconomic status

\section{INTRODUCTION}

Being the sixth common type of cancer in the world, oral cancer incidence remains high in developing countries with 275,000 incidence annually (Warnakulasuriya, 2009). Public awareness on oral cancer was reported to be lower compared to other types of cancer (Prayman et al., 2009). In some study population, they failed to recognise the early signs and symptoms of oral cancer such as red or white patches and unhealed ulcer (Amarasinghe et al., 2010; Devadiga and Prasad, 2010). Lack of knowledge on 
early signs and symptoms and the risk factor of oral cancer are the main factors that contribute to delayed presentation (Monteiro et al., 2012). Since early presentation could improve quality of life, reduce morbidity and mortality, the ability to recognise the early sign and symptoms is very crucial for everybody (Ghani et al., 2013).

In Malaysia, oral cancer contributes to about $10.6 \%$ deaths in government hospitals (Omar et al., 2006) whereby relatively high percentage $(67.1 \%)$ of cases were detected at advanced stage (Doss et al., 2011). This fact is attributed by the lack of awareness and knowledge especially the sign and symptoms of oral cancer (Ghani et al., 2013). Being multi-racial in Malaysia, oral cancer incidence varies by ethnic group whereby half of the oral cancer cases in Malaysia were among the Indian population (Ghani et al., 2019). This could be due to the prevalent betel quid chewing habit among the Indians which also suggests that the occurrence of oral cancer is predisposed by lifestyle and cultural practices (Ghani et al., 2019).

Oral screening is an easy and cheap method to detect pre-cancer or early stage oral cancer (Patton et al., 2004). However, detection of oral cancer frequently takes place at late clinical stage (Kumar and Green, 2005). Factors that influence the uptake of oral cancer screening are the awareness of the lesion and knowledge that the lesion could be easily detected by oral screening (Cruz et al., 2002).

Socioeconomic status is an important determinant of incidence of head and neck cancer (Chen et al., 2009). Health is strongly related to poverty (Wagstaff, 2002). Marginalised community is a group of people who are socially excluded and often forgotten due to several reasons such as economic status, access to education, or live in isolated places or depressed areas (Winchester and White, 1988). Low socioeconomic status has more tendency to develop poor health habits such as smoking and betel quid chewing which result in increase in mortality and morbidity rate among them (Melchior et al., 2007). It is also known that disadvantaged group make less use of the healthcare system for preventive purposes such as oral cancer screening and pap smear test (Turrell and Mathers, 2000). This fact could be due to lack of knowledge among them concerning the importance of early detection of cancer. Knowledge alone is insufficient to change the health behaviour, but it is a prerequisite.

Additionally, a systematic review and metaanalysis on socioeconomic inequalities and oral cancer risk had reported that the lower socioeconomic group has higher risk of oral cancer compared to those of higher socioeconomic group (Conway et al., 2008). In view of these circumstances, we aimed to assess the knowledge and awareness on oral cancer and its associated factors among the low socioeconomic group. In Malaysia, the knowledge and awareness on oral cancer had been previously studied among medical and dental students (Dubai et al., 2012), nonmedical background student (Musa et al., 2018) and general population (Ghani et al., 2013) but unfortunately, to the best of our knowledge, no such data is available on low socioeconomic group.

The Paya Nahu community in Sungai Petani, Kedah was appropriate population for this study as it matches the definition of low socioeconomic status based on Malaysia's per capita income whereby their income were less than RM3,000 (Ghani et al., 2019) and additionally because of their unconducive living environment and low education level. The outcome of this study could be highlighted to the authorities in improving the livelihood level of the community.

\section{MATERIALS AND METHODS}

This cross-sectional study was conducted during health campaign in a poor urban community of Paya Nahu in Sungai Petani, Kedah, Malaysia on 20th April 2019. This is a low-cost flat area which accommodates 
about 3,400 occupants. By using single proportion formula: $\mathrm{n}=(\mathrm{Z} / \Delta)^{2} \mathrm{p}(1-\mathrm{p})$ (Razak et al., 2010) whereby the precision was $0.1, \mathrm{p}=0.66$ (West et al., 2006), $\mathrm{Z}=1.96$ with $10 \%$ non-response rate, the sample size required was 95 , but the final subjects recruited were 96 , due to the last subject had requested to be included in the study. Convenient sampling was done to recruit subjects above 15 years old who can read and understand Malay or English language and our exclusion criteria were those who had oral cancer as their illness might have some influence on their knowledge on oral cancer. The participants were ushered to the survey counter by the researchers and they were briefed about the study. Informed consent was obtained from those who agreed to participate prior to answering the self-administered questionnaire. The researchers were available at all time to help the participants if they had any difficulty in answering the questionnaire. The answered questionnaires were collected immediately upon completion on the same day. A token of appreciation was given to the participants after the survey. This study was approved by Human Research Ethics Committee, Universiti Sains Malaysia (USM/ JEPeM/18040222).

\section{Research Tool}

The questionnaire was adopted from previous study (Musa et al., 2018) which had good internal reliability (Cronbach alpha 0.80-0.88). This questionnaire was a simplified version used by Ghani et al. (2013) in their study among the general population. It consisted of 3 sections A, B and C. Section A (A1-A10) assessed sociodemographic information; age, gender, ethnicity, education level, occupation, marital status, income, and smoking status. Section B assessed the respondent's awareness and knowledge which consisted of seven questions (B1-B7). Respondent was considered aware of oral cancer if they answered "Yes" for Question B2; "Have you heard regarding mouth cancer before?" For Question B3, there were seven answer choices for habits related to oral cancer: excess sugar intake, smoking, betel quid chewing, excess alcohol intake, eating spicy food, infrequent brushing teeth and excessive expose to sun. One mark was given to question B3 with scoring range from 0-7 marks. Items in B4, there were three answer choices with regards to early signs of oral cancer: white/red spot inside the mouth, unhealed mouth ulcer within two weeks and gum bleeding. On the other hand, item in $\mathrm{B} 5$ and B6, questions related to whether oral cancer can be treated more effectively at an early stage and is mouth self-examination one of the preventive steps for mouth cancer, respectively. Two marks were granted for every correct answer for items B4, B5 and B6, score ranging from $0-10$ marks. For item B7, assessed participant's opinion on where they could obtain information on prevention/ treatment for oral cancer; government clinic/hospital, private clinic/hospital/ traditional medicine centre, non-government organizations such as National Cancer Council Malaysia (MAKNA) and family members/friend, with score ranging from 0-5 marks. In this study, the total score for knowledge ranged from 0-22, respondents scoring 11 and below were considered as having poor knowledge and those scored above 12 as having good knowledge. Section $\mathrm{C}$ analysed the source of information on oral cancer.

\section{Statistical Analysis}

Data were entered and analysed using SPSS version 24. Categorical data was presented in percentage and frequency while numerical data was presented as mean and standard deviation to describe characteristic of the participants. Simple logistic and multiple logistic were used to analyse sociodemographic factors associated with knowledge at univariable and multivariable level, respectively. Independent factors that were included in the testing were age, gender, ethnic, education, income, marital status, occupation and smoking status. Variables with $p$-value less than 0.25 were subjected to multivariate analysis. By using forward and 
backward likelihood ratio test, the variables were further selected to be included in the model. This was followed by verification of the fit of the preliminary model and the importance of each of the variable. All interaction terms were checked, HosmerLemeshow goodness-of-fit test was carried out and area under the Receiver Operating Characteristic (Walsh et al., 2013) curve was obtained.

\section{RESULTS}

Sociodemographic characteristic of the respondents is shown in Table 1. Most of the respondents were females $(88.5 \%)$ and Malays $(91.7 \%)$. The mean age was 46.72 (SD 13.96) with minimum and maximum age of 15 and 78 years old, respectively. Majority of them only had secondary education (95.8\%), unemployed (68.0\%) and earned low income less than RM1,000 per month (79.0\%). Since none of the respondents earned more than RM3,000, we decided to regroup the income into only two groups; those who earned below RM1,000 and those above RM1,000 to facilitate analysis.

Table 2 has shown that $77 \%$ of the respondents were aware of oral cancer, however, they had poor knowledge on the details of oral cancer. Most of the respondents had poor knowledge on oral cancer with a mean score of 9.68 (SD 4.46) with minimum and maximum knowledge score of 1 and 18 respectively. Smoking was the most known risk factor for oral cancer with $64.6 \%$ answered correctly. Other risk factors such as alcohol, betel quid chewing and excessive exposure to sunlight were correctly answered with $38.5 \%, 35.4 \%$ and $19.8 \%$ of the respondents, respectively. Only half of the respondents knew about the early signs of oral cancer. Even though $77.1 \%$ of the respondents agreed to the benefit of early detection, but only $55.2 \%$ knew about mouth self-examination as a mean of oral cancer prevention.
Table 1 Sociodemographic characteristics of the subjects $(\mathrm{N}=96)$

\begin{tabular}{|c|c|c|}
\hline Variables & Frequency & Percentage (\%) \\
\hline \multicolumn{3}{|l|}{ Age } \\
\hline$<47$ years old & 44 & 45.8 \\
\hline$\geq 47$ years old & 52 & 54.2 \\
\hline \multicolumn{3}{|l|}{ Gender } \\
\hline Male & 11 & 11.5 \\
\hline Female & 85 & 88.5 \\
\hline \multicolumn{3}{|l|}{ Ethnic } \\
\hline Malay & 88 & 91.7 \\
\hline Non-Malay & 8 & 8.3 \\
\hline \multicolumn{3}{|l|}{ Marital } \\
\hline Married & 66 & 68.8 \\
\hline Unmarried/widow & 30 & 31.3 \\
\hline \multicolumn{3}{|l|}{ Education } \\
\hline Tertiary & 4 & 4.2 \\
\hline Secondary & 92 & 95.8 \\
\hline \multicolumn{3}{|l|}{ Occupation } \\
\hline Employed & 28 & 29.2 \\
\hline Unemployed & 68 & 70.8 \\
\hline \multicolumn{3}{|l|}{ Income } \\
\hline$>\mathrm{RM} 1,000$ & 17 & 17.7 \\
\hline$\leq \mathrm{RM} 1,000$ & 79 & 82.3 \\
\hline \multicolumn{3}{|l|}{ Smoking status } \\
\hline Smoker & 8 & 8.3 \\
\hline Non-smoker & 88 & 91.7 \\
\hline
\end{tabular}

Media, medical doctor/dentist, and health campaign were the main sources of information on oral cancer with $54.2 \%$, $51.0 \%$ and $50.0 \%$ respectively as shown in Table 3. Almost half of the respondents could not remember the last time they heard about oral cancer and advice by the medical doctor/dentist had the greatest impact on them.

Simple logistic regression (Table 4) shows that only age, ethnicity, income, and occupations has association with knowledge, however, further forward LR and backward LR showed only ethnicity and occupation as significant. Multiple logistic regression in Table 5 shows only occupation to be significantly associated with knowledge 
Table 2 Awareness and knowledge on early signs and risk factors of oral cancer

\begin{tabular}{|c|c|c|}
\hline & Yes $N(\%)$ & No $N(\%)$ \\
\hline \multicolumn{3}{|l|}{ Awareness } \\
\hline Have you heard regarding mouth cancer before? & $74(77.1)$ & $22(22.9)$ \\
\hline \multirow[t]{2}{*}{ Knowledge } & $\begin{array}{l}\text { mean knowledge } \\
9.68 \text { (SD 4.46) }\end{array}$ & \\
\hline & (Min-max 1-18) & \\
\hline \multicolumn{3}{|l|}{ Risk factors of oral cancer } \\
\hline Smoking & $62(64.6)$ & $34(35.4)$ \\
\hline Alcohol & $37(38.5)$ & $59(61.5)$ \\
\hline Spicy food & $26(27.1)$ & 70(72.9) \\
\hline Betel quid chewing & $34(35.4)$ & $62(64.6)$ \\
\hline Excessive UV exposure & 19(19.8) & $77(80.2)$ \\
\hline Excessive in sugar intake & 15(15.6) & $81(84.4)$ \\
\hline \multicolumn{3}{|l|}{ Early sign of oral cancer } \\
\hline Unhealed mouth ulcer & $49(51.0)$ & $47(49.0)$ \\
\hline White, red spot inside the oral cavity & $52(54.2)$ & $44(45.8)$ \\
\hline Bleeding gum & $51(53.1)$ & $45(46.9)$ \\
\hline Benefit of early detection & 74(77.1) & $22(22.9)$ \\
\hline Mouth self-examination as prevention & $54(55.2)$ & $42(44.8)$ \\
\hline
\end{tabular}

Table 3 Source of information on oral cancer

\begin{tabular}{lcc} 
Source of information & N & $\%$ \\
Source of information on mouth cancer & & \\
Internet & 26 & 27.1 \\
Medical dentist & 46 & 51.0 \\
Media & 52 & 54.2 \\
Health campaign & 50 & 50.0 \\
Family & 17 & 17.7 \\
Last time you heard about cancer & & \\
1-3 Weeks & 18 & 18.8 \\
A year ago & 18 & 18.8 \\
More than a month ago & 10 & 10.4 \\
Cannot remember & 46 & 47.9 \\
More than 3 months ago & 4 & 4.2 \\
Form of message given on mouth cancer & & \\
Documentary & 11 & 11.5 \\
Magazine, book, article & 28 & 29.2 \\
TV, radio, advertisement & 56 & 58.3 \\
Exhibition & 41 & 42.7 \\
Talk show & 16 & 16.7 \\
Information from medical or dentist & 11 & 11.5 \\
Biggest impact on you & & \\
Internet & 19 & 19.8 \\
Medical & 42 & 43.8 \\
Mass media & 32 & 33.3 \\
Health campaign & 30 & 31.3 \\
Family member & 19 & 19.8 \\
\hline
\end{tabular}


$(p=0.0298)$. The unemployed respondents had 0.33 time the odds compared to the employed to have good knowledge (95\% CI: $0.120,0.890, p$-value $<0.029)$ when adjusted for occupation. Results of the
Hosmer-Lemeshow model fitness test were not significant $(p=0.934)$ and the area under the ROC curve was 0.641 which is less than 0.7. This model can accurately discriminate $64 \%$ of the outcome.

Table 4 Factors associated with knowledge using simple logistic regression

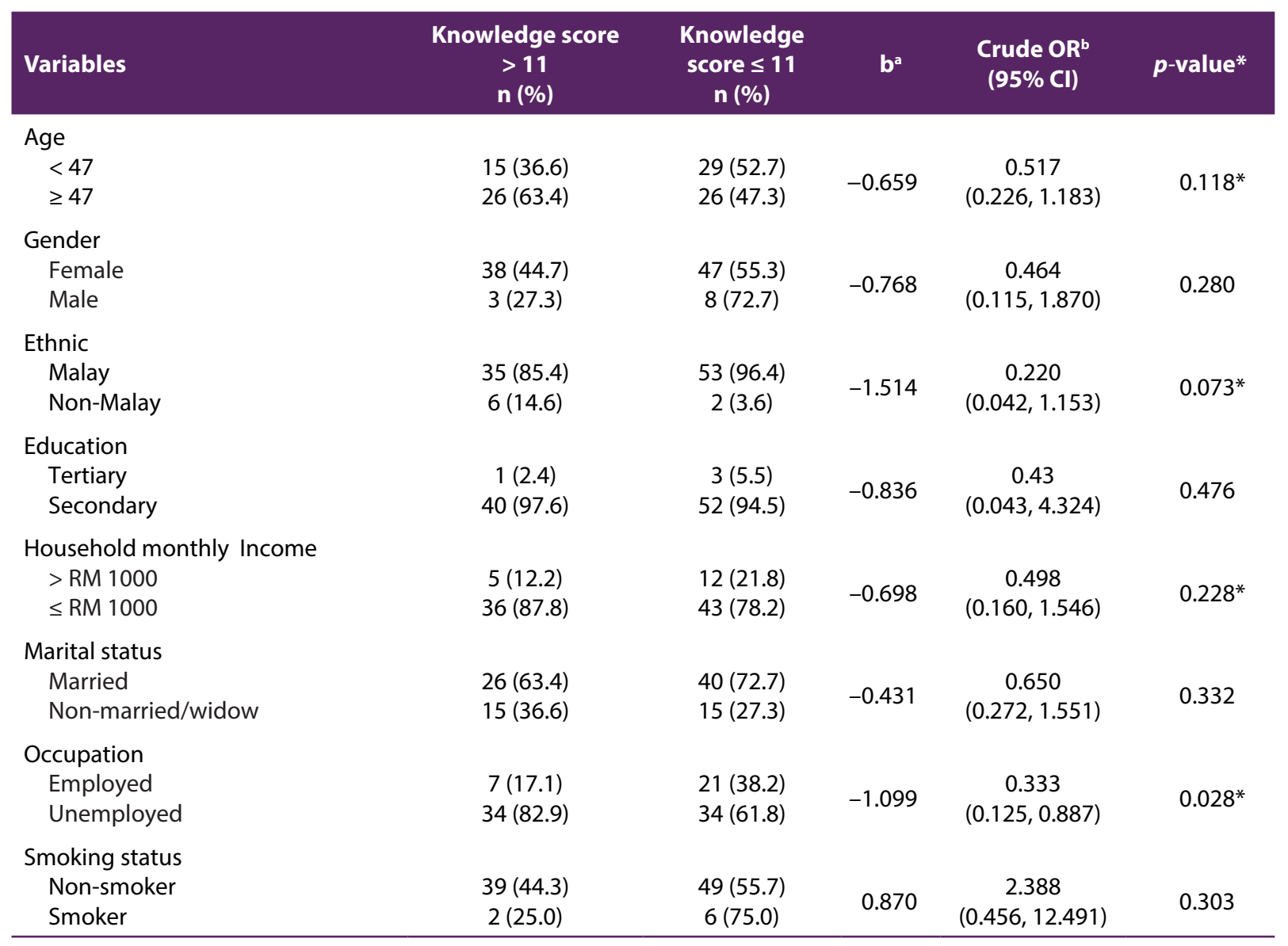

*SLR $-p<0.25$ sig

aRegression Coefficient, ${ }^{\mathrm{b}}$ Crude Odds Ratio

Table 5 Factors associated with knowledge test by multiple logistic regression

\begin{tabular}{lcccc} 
Variables & $\mathbf{b}^{\mathbf{a}}$ & $\begin{array}{c}\text { Adjusted } \mathbf{O R}^{\mathbf{b}} \\
(\mathbf{9 5 \%} \mathbf{C I})^{\mathbf{c}}\end{array}$ & Wald statistic & $\boldsymbol{p}^{\text {-value }}$ \\
\hline $\begin{array}{l}\text { Ethnic } \\
\quad \text { Malay } \\
\quad \text { Non-Malay }\end{array}$ & -1.552 & $\begin{array}{c}0.212 \\
(1.038,1.166)\end{array}$ & 3.181 & 0.074 \\
$\begin{array}{l}\text { Occupation } \\
\text { Employed } \\
\quad \text { Unemployed }\end{array}$ & -1.119 & 0.327 & & \\
\hline
\end{tabular}

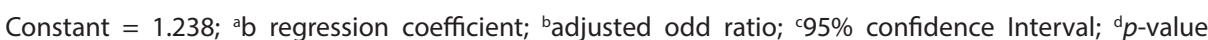
MLR < 0.05 significant; Interaction checked and not found; Hosmer-Lemeshow test $(p=0.934)$; Classification table (61.5\%); Area under ROC curve $=64.1 \%$ 


\section{DISCUSSION}

This low-cost flat area of Paya Nahu is situated right in the centre of Sungai Petani town in the state of Kedah, Malaysia. The population of Paya Nahu comprised of low socio-economic status (SES) as majority of them earned less than RM1,000 and none of them earned more than RM3,000. Based on Malaysia's per capita income, low SES is defined as earning less than RM3,000 $(\approx$ USD740)/month (Ghani et al., 2019).

This study was conducted during a health campaign. Out of the 3,400 occupants, only about $400(11.8 \%)$ of them attended the campaign. We managed to recruit $24 \%$ of those who attended the campaign to participate in the study and most of them were Malays, females, and elderly group. We believe this is the usual scenario in many activities conducted in this community. It is a challenge to achieve full participation of the occupants.

This study showed that even though their awareness was fairly high (77\%), but it was not as good as the previous study done on general population (85\%) which captured population of various socio-economic backgrounds (Ghani et al., 2013). The indepth knowledge on oral cancer of the subjects in this study were lower than the previous study (Musa et al., 2018) using the same questionnaire with mean knowledge score of 9.68 (SD 4.46) and 11.4 (SD 3.49) respectively. However, these findings could be influenced by the different background of the subjects whereby the later consisted of students between 20-24 years old wherein majority were males and unmarried. Nevertheless, smoking was the well-known risk factor of oral cancer which is similar to other previous studies (Prayman et al., 2009, Ghani et al., 2013).

It was observed that in this study, 8 out of 11 males were smokers and this may imply that the number of smokers was quite high among the males in this community. This scenario is a norm in low socio-economic community as smoking is a way of coping with their stressful and hard life (Krueger and Chang, 2008). Furthermore, being low educated, they tend to underestimate the health related hazards of smoking (Peretti-Watel et al., 2007).

Since majority of the respondents were Malays who are typically Muslims, drinking alcohol is prohibited, thus, little is known about alcohol being one of the risk factor which is similar to the finding in previous study on non-medical background students (Musa et al., 2018). Betel quid chewing was popular in the rural area and among elderly people. Nowadays, we can hardly find this activity, especially in town. This could be the reason the respondents were oblivious to this activity and similar result could be seen in previous studies in Malaysia (Ghani et al., 2013, Musa et al., 2018). Little is known about excessive exposure to sunlight that could cause oral cancer which is reflected in our result as only $19 \%$ of the respondents answered correctly which is concordant with previous studies (Al-Maweri et al., 2015, Musa et al., 2018). This could be attributed by rare cases of lip cancer in Malaysia compared to white population countries (Warnakulasuriya, 2009) where outdoor activities are popular (Musa et al., 2018).

About half of the respondents recognise the early signs and symptoms of oral cancer and $77.1 \%$ agreed with the benefit of early detection, only $55 \%$ knew that mouth selfexamination (MSE) as mean of oral cancer prevention. Even though they knew about MSE, it is questionable whether they knew how to do the examination. Unfortunately, this study did not include collection of such data. Knowing the signs and symptoms and benefit of early detection of oral cancer but not realising its existence in their mouth is very detrimental. We believe MSE is a very useful tool to detect oral cancer especially among the low-income society as it does not require any specialised instrumentation and does not incur any cost. However, many of high-risk group think that regular dental check-up with the dentist is adequate to 
respond to oral cancer prevention. That is the reason why opportunistic screening by dentist still remain the vital means of oral cancer detection (Sankaranarayanan et al., 2013). Unfortunately, the high-risk patients are usually from the low socio-economic income, a factor which also restricts regular attendance to the dentist. This fact is supported by previous study done in United States (Johnson et al., 2012). This matter may be addressed by dissemination of pamphlets on MSE or visual media to the public (Walsh et al., 2013). Additionally, this could be achieved as this study showed that most of the information on oral cancer were through media and health campaign which is in concordance with the previous studies (Ghani et al., 2013; Al-Maweri et al., 2015; Musa et al., 2018). Their lack of knowledge on oral cancer also implies that the existing health campaigns are insufficient to educate them and need to be improved. Furthermore, we believe many health campaigns do not target the low socio-economic and marginalised group which need to be addressed.

Internet has little contribution as source of information on oral cancer in this community. This could be attributed by the cost of the internet service, and not being accustomed to internet usage due to their age (54.2\% of the respondents were 47 years old and above) and majority being low educated (95.8\% had secondary education level).

Dentist is the most appropriate person to give advice on oral cancer as they have direct visibility to oral cavity (Saleh et al., 2014). This study showed that even though only $11.0 \%$ of the information came from the medical doctor and dentist, but it had the highest impact to the respondents compared to other source of information. This could be due to the advice given which were more personalised to the patient. Therefore, dentists should be more aggressive in disseminating information on oral cancer to the public and at the same time implementing opportunistic screening. Despite $84.4 \%$ of the respondents dentists who attended dental conference admitted that they implemented opportunistic screening (Saleh et al., 2014), knowledge on oral cancer are still low among public. This suggests that dissemination of information on oral cancer should be done concurrently with opportunistic screening.

The unemployed respondents had better knowledge on oral cancer compared to employed respondents. This is not a surprising finding as the main source of information was media, the unemployed respondents could have received the information on oral cancer from television, radio and advertisement (Ghani et al., 2013). Moreover, they have more time to spend socialising and could have received the information from friends.

The limitation of this study was very few male subjects had participated in the study which may not be representative of the community of Paya Nahu. This fact could also contribute bias to the number of unemployed participants (68\%) which consisted of pensioners, housewives and students. Majority of the participants were Malays $(91.7 \%)$ which could also contribute to bias, especially regarding knowledge on betel quid chewing habits which is more popular among the Indians. Additionally, the previous study (Ghani et al., 2013) had shown that the Indians were more aware of the detrimental effect of betel quid chewing compared to other ethnicity. Since the model could accurately discriminate only $64 \%$ of the outcome, there are some other factors which are not being studied.

Socio-economic status is a determinant of health and being low socio-economic, they are at higher risk to acquire diseases including cancer (Chen et al., 2009). At the same time, low socio-economic status is a factor which restricts health seeking behaviour. Effective outreach programme, improved health campaign and informative media on oral cancer should be emphasised. Assessment on MSE should be carried out among the marginalised group and should 
educate them with this cheap and useful method to detect oral cancer.

\section{CONCLUSION}

Although the respondents' awareness on oral cancer were fairly good but the knowledge on the sign and symptoms and risk factors of oral cancer was poor. Associated factors that influence knowledge among the marginalised group are ethnicity and occupation. Media, dentists, medical doctors and health campaigns were the main source of information on oral cancer.

\section{ACKNOWLEDGEMENTS}

We would like to express our gratitude to CIMB Foundation grant (dated: $5^{\text {th }}$ March 2018) for supporting this project and all the staffs who were directly and indirectly involved with the health campaign.

\section{REFERENCES}

Al-Maweri SA, Tarakji B, Alsalhani AB, AlShamiri HM, Alaizari NA, Altamimi MAS et al. (2015). Oral cancer awareness of the general public in Saudi Arabia. Asian Pac $\mathcal{F}$ Cancer Prev, 16(8): 3377-3381. https://doi. org/10.7314/apjcp.2015.16.8.3377

Amarasinghe HK, Usgodaarachchi US, Johnson NW, Lalloo R, Warnakulasuriya S (2010). Public awareness of oral cancer, of oral potentially malignant disorders and of their risk factors in some rural populations in Sri Lanka. Community Dent Oral Epidemiol, 38(6): 540-548. https://doi.org/10.1111/ j.1600-0528.2010.00566.x

Chen DT, Chou YF, Wu HP, Hsu LP, Wen IS, Lee CF et al. (2009). Income and the incidence of oral cavity cancer: Crossnational study. $\mathcal{F}$ Otolaryngol Head Neck Surg, 38(2): 208-211.
Conway DI, Petticrew M, Marlborough H, Berthiller J, Hashibe M, Macpherson LM (2008). Socioeconomic inequalities and oral cancer risk: A systematic review and meta-analysis of case-control studies. Int f Cancer, 122(12): 2811-2819. https://doi .org/10.1002/ijc.23430

Cruz GD, Le Geros RZ, Ostroff JS, Hay JL, Kenigsberg H, Franklin DM (2002). Oral cancer knowledge, risk factors and characteristics of subjects in a large oral cancer screening program. If Am Dent Assoc, 133(8): 1064-1071. https://doi.org/ 10.14219/jada.archive.2002.0330

Devadiga A, Prasad KVV (2010). Knowledge about oral cancer in adults attending a dental hospital in India. Asian Pac $\mathcal{F}$ Cancer Prev, 11(6): 1609-1613.

Doss JG, Thomson WM, Drummond BK, Raja Latifah RJ (2011). Validity of the FACT-H\&N (v 4.0) among Malaysian oral cancer patients. Oral Oncol, 47(7): 648-652. https://doi.org/10.1016/j. oraloncology.2011.04.023

Dubai SA, Ganasegeran K, Alabsi AM, Alshagga MA, Ali RS (2012). Awareness and knowledge of oral cancer among university students in Malaysia. Asian Pac f Cancer Prev, 13(1): 165-168. https://doi. org/10.7314/apjcp.2012.13.1.165

Ghani WMN, Doss JG, Jamaluddin M, Kamaruzaman D, Zain RB (2013). Oral cancer awareness and its determinants among a selected Malaysian population. Asian Pac f Cancer Prev, 14(3): 19571963. https://doi.org/10.7314/apjcp.2013 .14 .3 .1957

Ghani WMN, Razak IA, Doss JG, Yang YH, Abdul Rahman ZA, Ismail SM et al. (2019). Multi-ethnic variations in the practice of oral cancer risk habits in a developing country. Oral Dis, 25(2): 447455. https://doi.org/10.1111/odi.12995 
Johnson S, McDonald JT, Corsten M (2012). Oral cancer screening and socioeconomic status. F Otolaryngol Head Neck Surg, 41(2): 102-107.

Krueger PM, Chang VW (2008). Being poor and coping with stress: Health behaviors and the risk of death. Am $\mathcal{F}$ Public Health, 98(5): 889-896. https://doi.org/10.2105/ AJPH.2007.114454

Kumar JV, Green EL (2005). Oral health disparities in New York state. NY State Dent F, 71(7): 43-47.

Melchior M, Moffitt TE, Milne BJ, Poulton R, Caspi A (2007). Why do children from socioeconomically disadvantaged families suffer from poor health when they reach adulthood? A life-course study. $A m \mathcal{F}$ Epidemiol, 166(8): 966-974. https:/doi. org/10.1093/aje/kwm 155

Monteiro LS, Salazar F, Pacheco J, Warnakulasuriya S (2012). Oral cancer awareness and knowledge in the city of Valongo, Portugal. Int $\mathcal{f}$ Dent, 2012:376838. https://doi.org/10.1155/ $2012 / 376838$

Musa RAA, Shahabudin S, Mohd Noor SNF, Hami R (2018). The awareness and knowledge on oral cancer and its relation towards smoking habit among non-medical background students. Arch Orofac Sci, 13(2): 70-79.

Omar ZA, Mohd Ali Z, Ibrahim Tamin NS (eds.) (2006). Malaysian cancer statistics: Data and figure, Peninsular Malaysia 2006. Putrajaya: National Cancer Registry, Ministry of Health Malaysia.

Patton LL, Agans R, Elter JR, Southerland JH, Strauss RP, Kalsbeek WD (2004). Oral cancer knowledge and examination experiences among North Carolina adults. f Public Health Dent, 64(3): 173-180. https://doi.org/10.1111/j.1752-7325.2004. tb02748.x
Peretti-Watel P, Constance J, Guilbert P, Gautier A, Beck F, Moatti JP (2007). Smoking too few cigarettes to be at risk? Smokers' perceptions of risk and risk denial, a French survey. Tob Control, 16(5): 351-356. https://doi.org/10.1136/tc.2007.020362

Prayman E, Yang YH, Warnakulasuriya $S$ (2009). Oral cancer awareness of patients attending health centres In Trinidad. Int $\mathcal{F}$ Clin Dent, 2(4): 207-218.

Razak AA, Saddki N, Naing NN, Abdullah $\mathrm{N}$ (2010). Oral cancer survival among Malay patients in Hospital Universiti Sains Malaysia, Kelantan. Asian Pac $\mathcal{f}$ Cancer Prev, 11(1): 187-191.

Saleh A, Kong YH, Vengu N, Badrudeen H, Zain RB, Cheong SC (2014). Dentists' perception of the role they play in early detection of oral cancer. Asian Pac $\mathcal{F}$ Cancer Prev, 15(1): 229-237. https://doi.org/10 $.7314 /$ apjcp.2014.15.1.229

Sankaranarayanan R, Ramadas K, Thara S, Muwonge R, Thomas G, Anju G et al. (2013). Long term effect of visual screening on oral cancer incidence and mortality in a randomized trial in Kerala, India. Oral Oncol, 49(4): 314-321. https://doi. org/10.1016/j.oraloncology.2012.11.004

Turrell G, Mathers CD (2000). Socioeconomic status and health in Australia. Med $\mathcal{F}$ Aust, 172(9): 434-438.

Wagstaff A (2002). Poverty and health sector inequalities. Bull World Health Organ, 80(2): 97-105.

Walsh T, Liu JL, Brocklehurst P, Glenny AM, Lingen M, Kerr AR et al. (2013). Clinical assessment to screen for the detection of oral cavity cancer and potentially malignant disorders in apparently healthy adults. Cochrane Database Syst Rev, 2013(11): CD010173. https://doi. org/10.1002/14651858.CD010173.pub2 
Warnakulasuriya S (2009). Global epidemiology of oral and oropharyngeal cancer. Oral Oncol, 45(4-5): 309-316. https://doi.org/10 $.1016 /$ j.oraloncology.2008.06.002

West R, Alkhatib MN, McNeill A, Bedi R (2006). Awareness of mouth cancer in Great Britain. Br Dent F, 200(3): 167-151. https://doi.org/10.1038/sj.bdj.4813197
Winchester HPM, White PE (1988). The location of marginalised groups in the inner city. Environ Plan D Soc Space, 6(1): 37-54. https://doi.org/10.1068/d060037 